\title{
Controle da raiva no Brasil de 1980 a 1990
}

\section{Rabies control in Brazil from 1980 to 1990}

\author{
Maria Cristina Schneider, George A. de Almeida, Lúcia Maria Souza, Nélio B. de Morares \\ e Roberta C. Diaz
}

Fundação Nacional de Saúde/Ministério da Saúde. Rio de Janeiro, RJ - Brasil (M.C.S.; G.A.A.;

L.M.S.); Secretaria da Saúde do Estado do Ceará. Fortaleza, CE - Brasil (N.B.M); Instituto Nacional de Saúde Pública. México (R.C.D.)

\begin{abstract}
Resumo
Descreve-se a situação epidemiológica da raiva no Brasil no período de 19801990, em que o Programa Nacional de Profilaxia da Raiva foi estruturado em todo País. São mostradas as principais ações de controle da raiva desenvolvidas para se chegar aos resultados, considerados positivos. A raiva no Brasil registrou uma redução importante nos casos humanos $(78 \%)$ e caninos $(90 \%)$ na metade da série analisada. No final da década, houve um recrudescimento de casos em algumas partes do País, principalmente na região Nordeste que apresentou $70 \%$ dos casos em 1990. A raiva humana transmitida por morcegos também apresentou um incremento importante, chegando a $15,1 \%$ do total. O programa executado pelos Estados e municípios atende a 350.000 pessoas agredidas por animais e também vacina cerca de 9.000 .000 de animais anualmente. A vigilância epidemiológica é considerada fundamental e para isso se elaboraram indicadores para a definição de áreas de risco.
\end{abstract}

Raiva, prevenção \& cotrole. Avaliação de resultado de ações preventivas

\begin{abstract}
The epidemiological situation of rabies in Brazil at the period of 1980 to 1990, when the National Program for Rabies Prevention was implemented on a national scale, and which yielded positive results, is presented. The main controling actions carried out in order to achieve these results are also described. Rabies in Brasil registered a considerable decrease in human and canine cases (78\% and 90\%, respectively), half way through the series of analyses undertaken for this study. Towards the end of the decade, the disease began to recrudesce, several cases occurring in some parts of the country, mainly in the northeastern region, where 70\% of the total number of infections for 1990 was recorded. Moreover, human rabies transmitted by bats experienced a considerable increase, accounting for $15.1 \%$ of the total. The Program, which is implemented by State and Municipal authorities. Covers the 350,000 people who are attacked by animals, and vaccinates approximately 9,000,000 animals every annually year. Epidemiological control is considered to be of basic importance, so that indicators for the definition of the areas of risk have been developed.
\end{abstract}

Rabies, prevention and control. Evaluation of results of preventive actions. 


\section{INTRODUÇÃO}

A raiva é um problema de saúde pública desde tempos imemoriáveis ${ }^{1}$. Desde a descoberta da vacina contra a raiva por Pasteur há mais de um século ${ }^{8}$, a situação epidemiológica desta enfermidade vem mudando. Alguns países conseguiram se livrar dessa doença, como por exemplo a Inglaterra e a Austrália ${ }^{11}$. Outros mantêm o ciclo urbano da raiva sobre controle, ocorrendo apenas casos esporádicos transmitidos por animais selvagens, como é o caso dos Estados Unidos e alguns países da Europa ${ }^{11}$. Vários países da América Latina ainda não conseguiram controlar o ciclo urbano da raiva, no qual o cão é o principal transmissor ${ }^{6}$. Entre esses se encontra o Brasil, apesar dos grandes avanços ocorridos no controle da raiva, em grande parte do País.

O Brasil, porém, não é o País com os maiores coeficientes de mortalidade por raiva humana da América Latina. Em 1990, o Peru e o México apresentaram, respectivamente, coeficientes de 0,27 (63 casos) e 0,09 (69 casos) por mil habitantes ${ }^{6}$. Existem países fora da América Latina que também não conseguiram controlar a raiva, como por exemplo a Índia, onde se estima a ocorrência de aproximadamente 25.000 casos anuais de raiva humana ${ }^{11}$.

A eliminação da raiva nas Américas tem sido tema de várias reuniões internacionais nas últimas décadas, entre elas se destaca a Reunião de Guaiaquil, onde os países firmaram um plano de ação conjunta com o objetivo de eliminar a raiva urbana das grandes cidades das Américas, até o final da década de $1980^{7}$.

O presente trabalho analisa como se desenvolveram as principais ações de controle da raiva no Brasil e seu resultado sobre a situação epidemiológica. Considerou-se o período entre os anos 80 e 90 como o mais importante para estudo do controle da raiva no Brasil. Na série analisada no presente estudo o programa já estava estruturado e começando a apresentar bons resultados, com uma redução importante dos casos humanos e caninos após uma década de trabalhos intensivos.

\section{ESTRUTURA DO PROGRAMA NACIONAL DE PROFILAXIA DA RAIVA}

O Programa Nacional de Profilaxia da Raiva (PNPR) foi criado no Brasil em 1973 como um dos programas prioritários da política nacional de saúde. Esse Programa foi instituído mediante convênio firmado entre o Ministério da Saúde, o da Agricultura, a Central de Medicamentos e a Organização Pan-
Americana de Saúde/Organização Mundial da Saúde (OPAS/OMS). O objetivo do Programa foi promover, no país, atividades sistemáticas de combate à raiva humana, mediante o controle dessa zoonose nos animais domésticos e o tratamento específico das pessoas mordidas ou que, se supõe, tenham tido contato com animais raivosos 5 .

A então Fundação de Serviços de Saúde Pública, hoje na Fundação Nacional de Saúde (FNS), vinculada ao Ministério da Saúde (MS), foi escolhida para coordenar nacionalmente o Programa.

A criação do PNPR permitiu a elaboração e implantação de normas técnicas para o controle da enfermidade, a elaboração de um padrão na produção e controle de imunobiológicos utilizados no controle da raiva e também no abastecimento das Secretarias Estaduais de Saúde. O diagnóstico de laboratório foi implantado mediante a criação de novos laboratórios e o treinamento de pessoal. Instituiu-se também um sistema de vigilância epidemiológica da raiva ${ }^{5}$.

A coordenação e execução do PNPR está a cargo das Secretarias Estaduais de Saúde, sendo que em alguns Estados foi também constituída uma comissão estadual de controle da raiva. Vários dos grandes municípios do País executam e coordenam suas atividades nesse nível. O controle da raiva em herbívoros está a cargo do Ministério da Agricultura.

O programa estabelecido gradualmente em todo o País começou suas atividades nas zonas urbanas das capitais e regiões metropolitanas, estendendose, posteriormente, às cidades do interior e à zona rural, atendendo à totalidade dos Estados, a partir de 1977.

Toda vacina para uso humano e canino (ambas de tipo Fuenzalida Palacios), utilizada pelo Programa, é produzida e controlada no Brasil. Anualmente, são distribuídas cerca de 2.500 .000 doses humanas e 15.000.000 de doses caninas.

Schneider ${ }^{10}$ mencionou que em 1986 existiam 5.007 unidades de saúde com tratamento grátis contra a raiva, representando $16,2 \%$ do total de unidades existentes no Brasil e cobrindo $86 \%$ do total de municípios existentes (Tabela).

Para a campanha de vacinação canina o Programa recebe ajuda de várias instituições: instituições agrícolas, universidades, forças armadas e outras, bem como da própria FNS que conta com uma rede importante de atendimento nas regiões Norte e Nordeste do País.

Existiam no Brasil, durante o período analisado, 16 Centros de Controle de Zoonoses (CCZ) em diversos Estados. Os centros têm como principal ati- 
Tabela - Número de habitantes; número de unidades de saúde existentes, número de unidades de saúde em tratamento contra a raiva, porcentagem de unidades com tratamento e proporção de unidades de saúde com tratamento por habitantes Brasil*, 1986.

\begin{tabular}{lrcrcc}
\hline Macro-regiões & $\begin{array}{c}\mathrm{N}^{\circ} \text { de } \\
\text { habitantes }\end{array}$ & $\begin{array}{c}\mathrm{N}^{\circ} \text { de US } \\
\text { existentes }\end{array}$ & $\begin{array}{c}\mathrm{N}^{\circ} \text { de US com } \\
\text { tratamento }\end{array}$ & $\begin{array}{c}\text { \% de US com } \\
\text { tratamento }\end{array}$ & $\begin{array}{c}\text { Proporção de US } \\
\text { com tratamento } \\
\text { por habitantes }\end{array}$ \\
\hline Norte & 8.079 .201 & 1.970 & 344 & 17,5 & $1: 34.675$ \\
Nordeste & 39.894 .463 & 9.546 & $1.421^{*}$ & 14,9 & $1: 28.075$ \\
Sudeste & 60.784 .706 & 11.443 & 2.093 & 18,3 & $1: 29.042$ \\
Sul & 20.949 .110 & 5.891 & 753 & 12,8 & $1: 27.859$ \\
Centro-oeste & 9.467 .681 & 2.022 & $396^{*}$ & 19,6 & $1: 23.908$ \\
\hline Total & 139.186 .459 & 30.872 & 5.007 & 16,2 & $1: 28.434$ \\
\hline
\end{tabular}

*Falta informação de um Estado.

Fonte: Schneider ${ }^{10}, 1990$

vidade o controle da raiva, mas também realizam outras ações de controle, como por exemplo, contra a leptospirose. Alguns desses centros, como os de São Paulo, do Rio de Janeiro e de Brasília, foram os primeiros desse tipo na América Latina e são considerados modelos internacionalmente. Houve uma importante contribuição na construção dos $\mathrm{CCZ}$ na década de 80 por parte da extinta Divisão Nacional de Zoonoses do Ministérios da Saúde, cuja atividade era independente do PNPR.

O PNPR, no Brasil, é sustentado unicamente com recursos nacionais, mas conta principalmente com o apoio da OPAS na capacitação de pessoal e consultorias técnicas. Não recebe fundos externos, como recebia a campanha de erradicação da poliomielite.

\section{SITUAÇÃO EPIDEMIOLÓGICA}

O Brasil vinha apresentando um número elevado de casos de raiva humana, tendo sido registrado, em 1980, um total de 168 casos (Coef. de 0,11 por 100 mil hab.)*. Em 1988, foram registrados 37 casos (Coef. 0,03 por 100 mil hab.), o que representou uma redução de $78 \%$ dos casos de raiva humana. Nos anos que se seguiram, até 1990, último ano analisado no presente estudo, houve um recrudescimento de casos em algumas áreas do País, chegando-se novamente a 70 casos de raiva humana (Coef. 0,05 por 100 mil hab.). A análise da tendência do período demonstra, por meio de uma regressão linear, uma redução estatisticamente significativa $(\mathrm{p}<0,05)$ na taxa de casos humanos, com uma $\beta=-0,0096$. Para a série analisada, isto significa que, em cada ano que passava, a taxa de mortalidade por raiva humana baixava em quase 0,01 (Fig. 1).

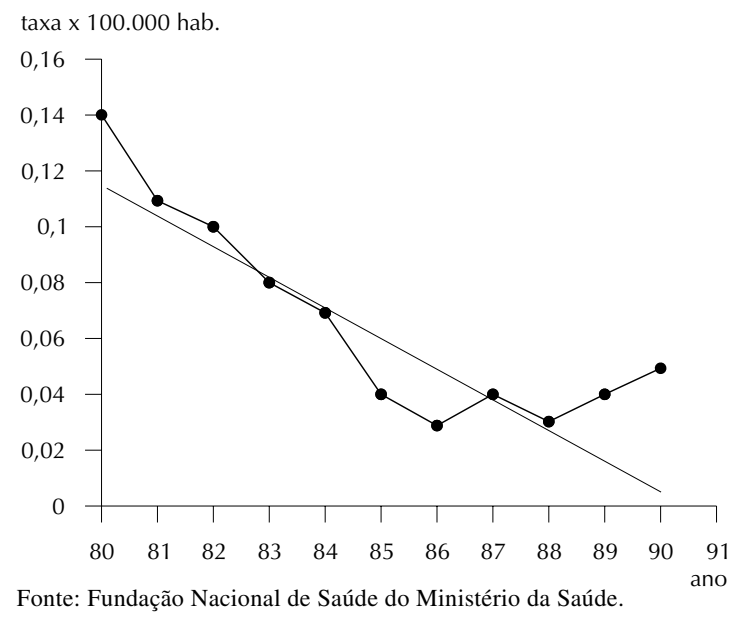

Figura 1 - Taxa de mortalidade por raiva humana e reta de regressão. Brasil, 1980-1990.

O aumento do número de casos humanos, nos últimos dois anos analisados, deu-se principalmente por dois fatores: recrudescimento da raiva canina em algumas áreas da região Nordeste e o aumento dos casos humanos transmitidos por morcegos.

A distribuição epidemiológica da raiva no Brasil é atualmente muito heterogênea. Nos últimos anos, cerca de $70 \%$ dos casos humanos foram registrados na região Nordeste, que é também uma das que apresentam maiores dificuldades econômicas no País (Fig. 2). Em 1990, 46,6\% dos casos ocorridos foram registrados em apenas três Estados (Maranhão, Alagoas e Bahia) (Fig. 3). Em compensação, a região Sul não apresenta casos humanos desde 1982, com exceção de um caso acidental transmitido por morcego perto da cidade de Curitiba-PR, em 1987. Esse Estado, que tem um dos melhores indicadores socioeconômicos do País, foi o primeiro a controlar

* Os dados apresentados no presente trabalho foram obtidos diretamente de diversos documentos existentes na Coordenação Nacional do PNPR. 


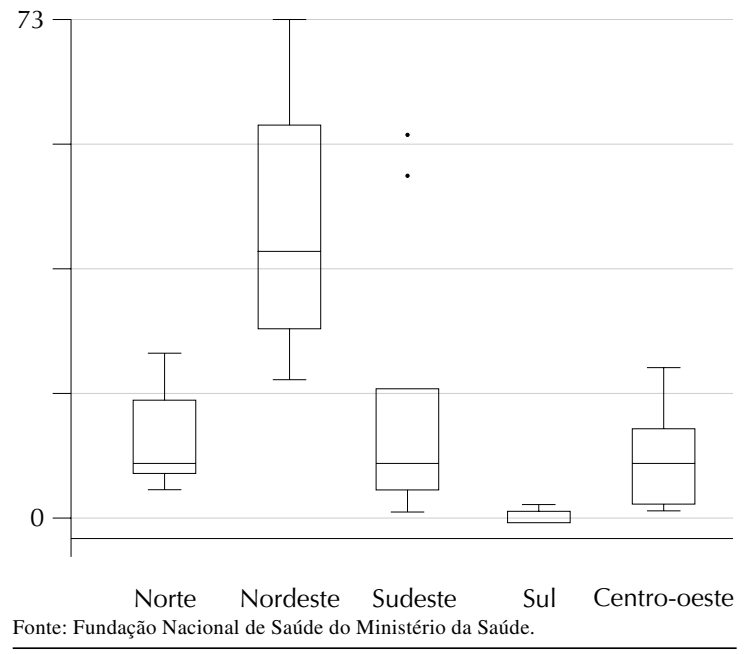

Figura 2 - "Box Plot" dos casos de raiva humana por macrorregiões. Brasil, 1980-1990.

a raiva, não registrando casos humanos transmitidos por cão desde 1977.

Nesse período, vários municípios brasileiros importantes conseguiram controlar a raiva, como é o caso de São Paulo, Rio de Janeiro, Brasília, Curitiba, Florianópolis, Porto Alegre e outros. Ao analisar-se a distribuição dos casos de raiva humana por município, verifica-se que, em 1990, esses ocorreram em 57 municípios, o que representa aproximadamente $1 \%$ do total de municípios existentes no Brasil.

Em 1980, 64,3\% dos casos humanos foram registrados na zona urbana; nos últimos anos da série analisada essa porcentagem diminuiu para cerca de $37 \%$. Analisando-se as taxas da zona rural e da

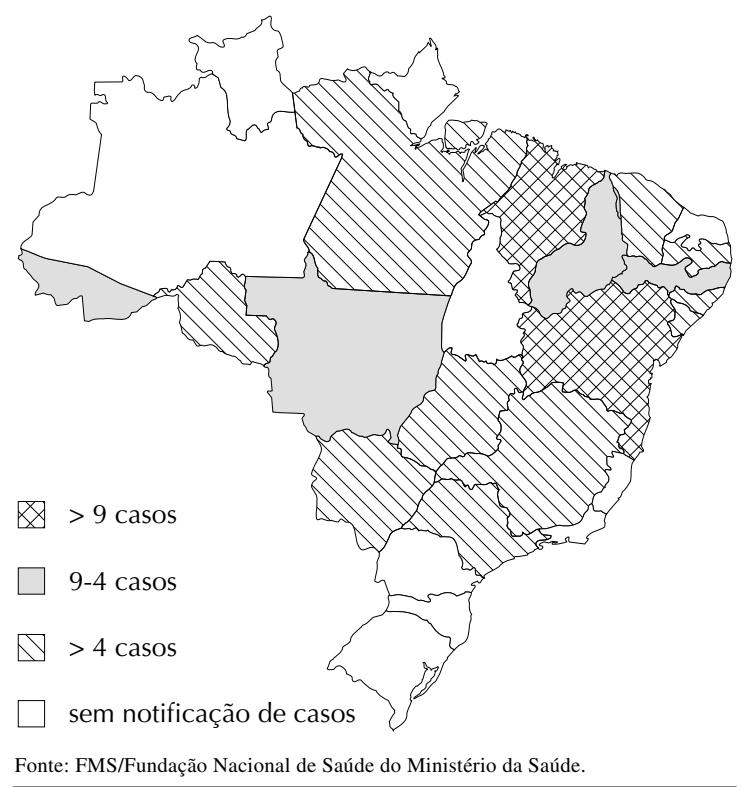

Figura 3 - Casos de raiva humana por unidade federativa. Brasil, 1990. zona urbana, a primeira apresentou, em 1990, valores seis vezes mais altos que a segunda. Os casos registrados nas capitais dos Estados reduziram-se a 2 (em 1987) e a 3 (em 1988), tendo aumentado nos dois anos seguintes devido, principalmente, a um surto na cidade de Maceió/Al (5 casos), totalizando 8 casos (12\% do total) em 1990.

O ciclo urbano da enfermidade continua sendo o mais importante, $83,2 \%$ do total de casos humanos foram transmitidos por cães durante o período estudado (Fig. 4). O segundo animal na escala de transmissão da raiva às pessoas é o morcego. Esse problema vinha aumentando desde 1985, chegando a 11 casos $(15,1 \%)$ transmitidos por esse animal, em $1990^{9}$.

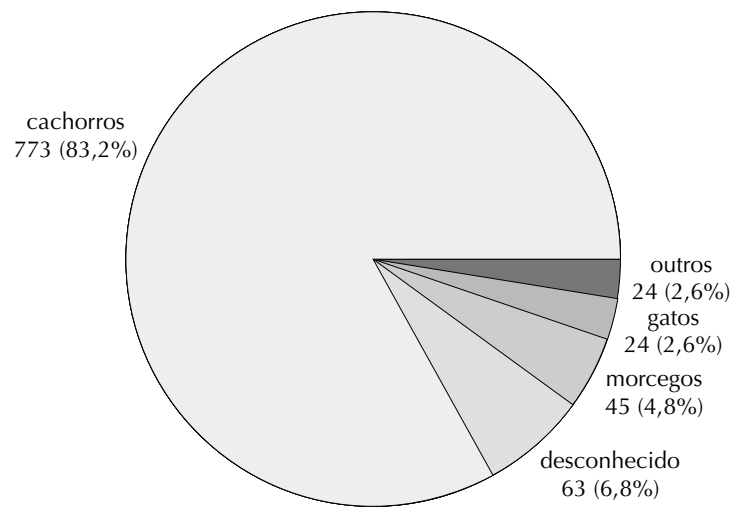

Fonte: Fundação Nacional de Saúde do Ministério da Saúde.

Figura 4 - Casos de raiva humana por tipo de animal agressor, 1980-1990.

O grupo que apresenta a maior taxa de mortalidade por raiva no Brasil são as crianças do sexo masculino entre 5 e 14 anos de idade, que represen$\operatorname{tam} 32,1 \%$ do total, provavelmente por estarem mais expostas, brincando nas ruas. Em relação ao nível profissional, não se registrou nenhum caso de raiva em pessoas com formação universitária, o que sugere que a raiva ocorre com maior frequiência entre pessoas do nível socioeconômico mais baixo.

Os casos de raiva humana distribuídos por mês de ocorrência entre 1980 e 1988 não apresentaram variação sazonal (Anova, $\mathrm{Fc}=0,56<\mathrm{Ft}=1,83$ g.1.= =11,96). A Figura 5 mostra as médias dos casos mensais e o limite máximo esperado (média mais dois desvios-padrão) que sugerem um pequeno aumento nos meses de março, julho e outubro ${ }^{10}$.

A raiva canina também apresentou uma diminuição importante nesse período. Em 1980, registraramse 4.570 casos (taxa de 38,38 por 100 mil cães), chegando a 464 (taxa de 3,16 por 100 mil cães) em 1988, o que representa uma redução de aproximadamente $90 \%$. Nos dois últimos casos analisados, houve também um 


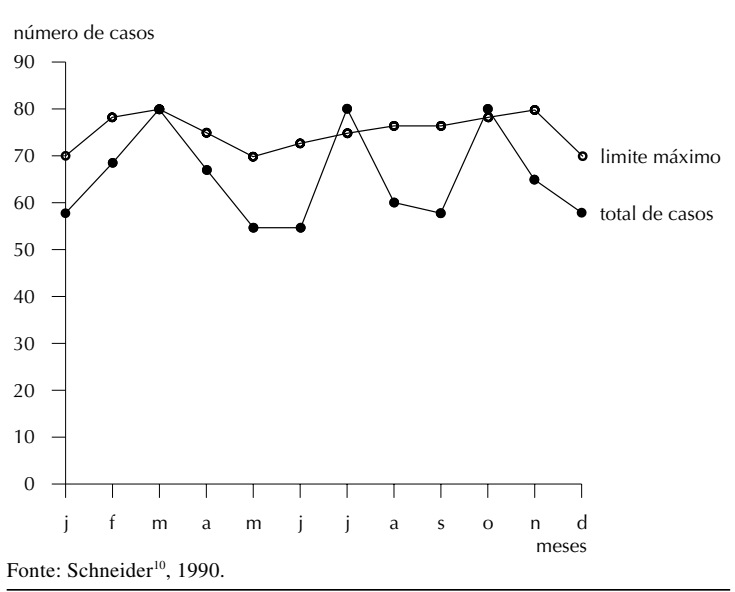

Figura 5 - Total de casos de raiva humana notificados e limite máximo esperado, por mês de ocorrência. Brasil, 1980-1990.

recrudescimento dos casos, tendo sido registrados 817 casos (taxa de 5,45 por 100 mil cães), em 1990. A reta de regressão do período analisado apresenta um signo negativo, com uma $\beta=-2,8124$, o que representou uma redução estatisticamente significativa $(\mathrm{p}<0,05)$ na taxa de mortalidade por raiva canina.

Embora a raiva animal nas diferentes espécies possa estar subestimada, o sistema de vigilância epidemiológica não mudou muito nessa década, o que permite fazer comparações para analisar a tendência da enfermidade no Brasil.

A raiva em outros animais domésticos, excluído o cão, não tem grande importância epidemiológica para a doença no Brasil. O número de gatos raivosos registrados durante o período estudado foi de aproximadamente $10 \%$ do número de cães raivosos. Isso sugere que ao se reduzir o número de cães com raiva, reduz-se proporcionalmente o número de gatos.

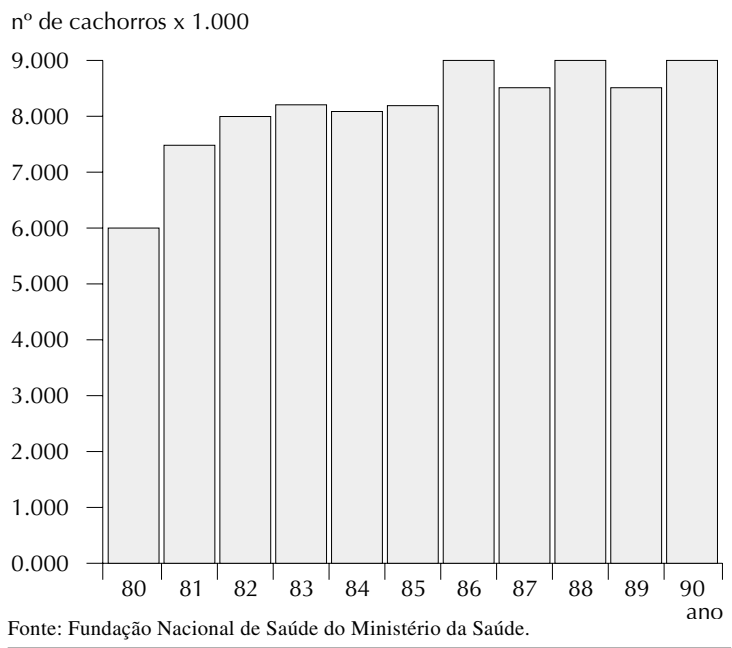

Figura 6 - Número de cachorros vacinados. Brasil, 19801990.

\section{PRINCIPAIS AÇÕES DESENVOLVIDAS}

As principais atividades básicas desenvolvidas pelo PNPR são²:

Tratamento preventivo contra a raiva humana

Vacinação canina

Captura de animais

Diagnóstico de laboratório

Vigilância epidemiológica

Educação em saúde

O tratamento preventivo da raiva humana e a vacinação canina são as duas principais ações de controle desenvolvidas no Brasil. Com a primeira, pretende-se diminuir a mortalidade humana, sem atuar no processo de transmissão. Com a segunda ação, procura-se diminuir a intensidade da transmissão. O objetivo primordial é interromper a transmissão às pessoas e, secundariamente, aos animais domésticos. Não se trata de erradicar a enfermidade no Brasil porque, com a circulação intensa do vírus rábico no ciclo silvestre, isto seria muito difícil atualmente.

Nos últimos anos, cerca de 350.000 pessoas foram atendidas anualmente na rede pública de saúde devido a ataques de animais, representando $0,14 \%$ do total de pessoas atendidas em questões de saúde em todo o País. Esse número cresceu muito desde que começou o PNPR, já que anteriormente era de 103.000 pessoas. O acréscimo do número de pessoas atendidas está diretamente associado à informação sobre o risco de contrair a doença e a acessibilidade aos serviços que constam do tratamento. Aproximadamente $45 \%$ das pessoas atendidas são tratadas; os outros casos são apenas de observação de animais, ou casos de ataque que não demandam tratamento ${ }^{3}$.

A percentagem de pessoas tratadas com soro e vacina aumentou muito (de 5,7\% a 20\%) nos últimos 2 anos analisados. Esse aumento ocorreu depois do início da importação de soro para complementar a quantidade produzida no Brasil.

A proporção de acidentes pós-vacinais com comprometimento do sistema nervoso central é de 1 para cada 34.533 pessoas tratadas (1/34.533) e destas $35 \%$ morrem $^{10}$.

A vacinação canina é ainda a principal ação do PNPR, onde se concentra grande parte dos esforços. Em 1980 eram vacinados cerca de 6.000.000 de animais por ano, a partir de 1986 esse número passou para aproximadamente 9.000.000. Noventa por cento desses animais eram cães e os dez por cento restantes gatos. 
Isto representa uma cobertura de cerca de $80 \%$ da meta estabelecida que é a de vacinar $80 \%$ da população canina estimada. Grande parte destes animais são vacinados em um só dia. Principalmente nas capitais estaduais, onde se realiza uma grande campanha de vacinação semelhante à da poliomielite para crianças. Pode-se observar que com o aumento do número de cães vacinados, diminuiu-se a taxa de mortalidade por raiva humana.

Alguns Estados da região Sul (Paraná e Santa Catarina), que conseguiram uma situação epidemiológica privilegiada, não realizaram mais campanhas de vacinação anuais, fazendo apenas bloqueio de surtos em casos de necessidade e uma boa vigilância epidemiológica.

Outra atividade fundamental é a vigilância epidemiológica na qual o diagnóstico de laboratório está incluído. Não se pode conhecer a situação epidemiológica sem a vigilância. Dependendo do estado de controle do lugar, esta ação adquire papel primordial.

Com base em uma análise da vigilância epidemiológica de algumas cidades do Brasil, Schneider ${ }^{10}$ sugeriu o envio anual de amostras equivalentes a $0,2 \%$ da população canina estimada para a área, com o fim de realizar diagnóstico laboratorial de raiva; isto permitiria considerar confiável a informação sobre a vigilância epidemiológica. Depois de utilizar este indicador em estudos de campo, chegou-se à conclusão de que somente $0,1 \%$ de amostras, a serem enviadas para diagnóstico, seria suficiente. Ainda assim, o Estado do Paraná definiu percentagens mais altas para uma área de foco e para a região fronteiriça.

Durante o período estudado, existiam no Brasil 34 laboratórios que realizavam diagnóstico de raiva, distribuídos em 28 municípios, 38\% deles localizados na região Sudeste. Esses laboratórios pertenciam a universidades ou diversas instituições da área de saúde e agricultura ${ }^{10}$. Aproximadamente, 12.000 amostras eram enviadas para diagnóstico a cada ano, sendo $50 \%$ delas de cães. O percentual de positividade das amostras enviadas teve uma redução importante; em 1980, 31,2\% delas eram positivas, passando em 1990 a $11,6 \%$.

Cerca de $60 \%$ dos animais agressores eram observados em canis públicos ou por seus donos com orientação apropriada. O controle de focos era também uma atividade importante para o controle da raiva. Considerava-se que o controle de foco deveria ser iniciado em menos de 72 horas, devendo ser vacinados todos os animais da área, de casa em casa, juntamente com a captura dos cães vadios, além da divulgação do problema à população, principalmen- te, para que procurasse atendimento imediato, em caso de agressão.

$\mathrm{O}$ número de animais capturados no Brasil não era muito significativo em termos de País, perto de 70.000 animais anualmente, porque esta atividade se concentrava apenas em algumas grandes cidades, como São Paulo, Belo Horizonte e Brasília. A captura de animais durante o controle de focos passou a ser considerada fundamental, mas a captura de rotina em áreas urbanas não demonstrou ser sempre necessária para que se consiga o controle da enfermidade. Curitiba, que foi a primeira cidade a conseguir controlar a raiva no Brasil, não realizava captura sistemática. Esta estratégia provavelmente depende da realidade local.

Outra atividade considerada parte das atividades oficiais do PNPR é a educação em saúde. Elaborouse série de materiais para divulgação das ações preventivas da enfermidade. Esse material é distribuído na época da campanha em áreas onde ocorreram surtos, serviços de saúde, escolas e outros lugares.

Durante vários anos o Governo Federal fez uma campanha de divulgação do PNPR, em nível nacional, na época da campanha de vacinação canina, utilizando rádio, televisão e outros meios de divulgação como sistemas locais de alto-falantes. Esta ação foi considerada um dos pontos importantes para se conseguir uma boa cobertura. As mensagens a serem divulgadas eram definidas em conjunto com os coordenadores estaduais de PNPR, optando-se quase sempre por um material de divulgação simples que toda a população, e em particular as crianças, pudesse entender e que também fosse facilmente reproduzido pelos Estados. No último ano analisado (1990) não houve campanha de divulgação em nível nacional, mas o Governo Federal destinou recursos financeiros para reforçar esta atividade nos Estados e municípios, recomendando formas locais de divulgação, como carros com alto-falantes, sistema de alto-falantes fixos e cartazes. O número de animais vacinados em 1990 manteve-se semelhante em relação à média nacional, independente do tipo de divulgação.

Não se considera que o PNPR tenha tido um programa de educação em saúde durante o período analisado, a não ser em algumas localidades. O Programa estava mais orientado para divulgação de ações básicas de profilaxia.

Uma outra atividade importante que vinha sendo desenvolvida pelo PNPR é a formação de recursos humanos. Durante a década analisada, o Programa de Raiva realizou série de cursos e reuniões técnicas, sendo que muitas delas em conjunto com as Se- 
cretarias Estaduais de Saúde, com o apoio de instituições de ensino e de pesquisa. Receberam orientação sobre o tema perto de 400 técnicos por ano que atuam no controle da raiva, como veterinários, médicos, enfermeiras, pessoal de laboratório e outros. Esse tipo de atividade conjunta periódica, além da atualização de técnicos, favoreceu a integração e união entre os mesmos.

Em função das diferentes situações epidemiológicas do País, um grupo de especialistas, sob a coordenação do PNPR, revisou a Norma Técnica de Tratamento Preventivo Contra a Raiva, definindo dois esquemas de tratamento a partir da situação de risco do município ${ }^{3}$. Um esquema seria para as áreas de baixo risco, em que se aconselhava a observação intensiva dos animais, em lugar de tratar as agressões graves por parte de animais observáveis, como era recomendado no segundo esquema para as demais regiões do País. A necessidade de definir epidemiologicamente as áreas de baixo risco levou à convocação de uma segunda reunião com especialistas, com a finalidade de elaborar uma metodologia para a avaliação de áreas de risco no Brasil ${ }^{4}$. No documento elaborado estabeleceram-se critérios epidemiológicos para se considerar uma área silenciosa, vulnerável e receptiva em relação à raiva.

Dando prosseguimento a esse tema, Schneider ${ }^{10}$ desenvolveu um instrumento que avalia a situação de risco para a raiva no Brasil que pode contribuir para a definição de estratégias a serem utilizadas para cada local. Esta metodologia foi adaptada para a realidade local pelos coordenadores estaduais do Programa.

\section{CONSIDERAÇÕES FINAIS}

O PNPR vem conseguindo bons resultados, a raiva humana e canina decresceu consideravelmente no Brasil, apesar do recrudescimento em algumas áreas e o aumento de casos humanos de transmissão por morcegos. Podemos sugerir que a raiva (ciclo urbano) no Brasil, ao final da série analisada, localiza-se em algumas áreas específicas principalmente na região Nordeste, que é uma das mais pobres do País, onde não é só a raiva que apresenta uma incidência elevada. Pode-se pensar ainda, que a raiva se encontra em municípios com problemas socioeconômicos maiores ou na periferia de algumas grandes cidades, onde vivem pessoas com baixa inserção no processo produtivo.

Observa-se uma associação direta entre o desenvolvimento de ações de controle e o resultado na di- minuição do número de casos de raiva. Em várias partes do Brasil demonstrou-se que é possível controlar esta enfermidade, principalmente nos Estados e municípios mais ricos onde o sistema de saúde é mais desenvolvido e as condições de vida das pessoas mais dignas.

As condições para se conseguir o controle da raiva são tecnicamente simples, mas não tão fáceis de serem executadas. Vacinar perto de 12.000 .000 cães anualmente (meta de $80 \%$ da população canina estimada para o Brasil em 1990) demanda muito esforço, apoio de várias instituições e recursos financeiros.

Atender satisfatoriamente as pessoas atacadas por animais depende, basicamente, do acesso aos serviços de saúde e da qualidade dos mesmos. A quantidade de vacinas e sua qualidade ao sair do laboratório não parece ser problema no Brasil, tanto que, nos locais onde as ações foram bem desenvolvidas os resultados foram excelentes. Não seria possível responder sobre a qualidade da rede de refrigeração, em algumas partes mais distantes do País.

Acredita-se ter havido no Brasil apoio político para o controle da raiva, visto que para tanto foi criada uma estrutura que apresentou bons resultados. $\mathrm{O}$ apoio à estrutura existente é variado e vai depender das prioridades dos dirigentes do setor de saúde a nível federal, estadual e municipal.

Caso se priorize, nos diversos níveis, esse apoio político de controlar da raiva no Brasil, com a atual estrutura socioeconômica do País, qual seria o número máximo de casos humanos que poderiam ocorrer para que se considerasse o programa de controle da raiva como bem sucedido, apesar de a meta interromper totalmente a transmissão desta enfermidade à população?

Para finalizar são apresentadas algumas recomendações:

a) Continuar procurando o apoio político para o controle da raiva através da análise profunda da situação, demonstrando as necessidades e as formas de se conseguir este controle;

b) Continuar com a estratégia de áreas de risco, definindo ações específicas para cada realidade dirigindo mais recursos para as áreas de maior risco;

c) Onde existirem condições técnicas, decentralisar ao máximo a aplicação do tratamento preventivo humano, melhorando a acessibilidade e supervisionando sua qualidade;

d) Procurar a integração entre os vários níveis, setores e instituições, principalmente com outros projetos já existentes, nas áreas de maior incidência, como é o caso do PCDEN (Projeto 
de Controle de Doenças Endêmicas do Nordeste);

e) Estudar as possibilidades de que os guardas sanitários e os agentes de saúde da Fundação Nacional de Saúde, que trabalham com o controle de outras doenças como a malária, atuem também no controle da raiva, principalmente em áreas de difícil acesso como é o caso da maior parte das zonas de risco de transmissão de raiva humana por morcegos;

\section{REFERÊNCIAS BIBLIOGRÁFICAS}

1. BAER, G.M. The natural history of rabies. Boca Raton, CRC Press, 1991.

2. BELOTTO, A.J. A raiva no Brasil em 1984; aspectos operacionais e epidemiológicos. Rev. Fund. SESP, 30:16782, 1985.

3. FUNDAÇÃO SESP. Norma técnica de tratamento preventivo contra a raiva humana. Rio de Janeiro, Ministério de Saúde, 1987.

4. FUNDAÇÃO SESP. Discussão sobre área de risco para a raiva no Brasil. Rio de Janeiro, Ministério de Saúde, 1987.

5. MINISTÉRIO DA SAÚDE. Programa nacional de profilaxia da raiva. Brasília, 1973.

6. ORGANIZACION PAMAMERICANA DE LA SALUD. Vigilancia epidemiologica de la rabia en las Américas. Buenos Aires, INPAZ, 1993. f) Pensar no controle da raiva em relação ao Sistema Único de Saúde, onde cada vez mais os municípios assumem a responsabilidade pela saúde de seus habitantes.

\section{AGRADECIMENTOS}

Ao Dr. Albino Beloto, ao Dr. Fernando Gomes e ao Dr. Eutimio Gonzales e a vários coordenadores estaduais, que estruturaram o Programa Nacional de Profilaxia da Raiva.

\section{ORGANIZACION PAMAMERICANA DE LA SALUD.}

Estrategia y plan de acción para la eliminación de la rabia urbana en América Latina para el final de la década 1980. Guayaquil, 1983.

8. PASTEUR, L. Oeuvres de Pasteur. Paris, Masson, 1933. v. 6: Maladies virulentes, virus vaccins et prophylatre de la rage.

9. SCHNEIDER, M. C. Situación epidemiológica de la rabia humana transmitida por murciélago en Brasil: el brote de Apiacas-MT. In: Reunión de Consulta Sobre la Atención a Personas Expuestas a la Rabia Transmitida por Vampiros, Washington, 1991. Anales. Washington, OPS, 1991.

10. SCHNEIDER, M. C. Estudo de avaliação sobre área de risco para a raiva no Brasil. Rio de Janeiro, 1990. [Dissertação de Mestrado - Escola Nacional de Saúde Pública da Fundação Oswaldo Cruz].

11. WORLD HEALTH ORGANIZATION. World survey of rabies, 22: for years 1984-85. Geneva, 1986. (WHO-Rabies-87.198). 